\title{
Strategy for Optimizing an F1 Car's Performance based on FIA Regulations
}

\author{
Karan Bopaiah and Stephen Samuel \\ Oxford Brookes University
}

\begin{abstract}
The aim of the present work is to propose a control strategy for maximizing the performance of a Formula One (F1) car through numerical simulation for 2021 regulations taking 2019 regulations as a benchmark. This study has developed an engine-powertrain model of an F1 car with real world driver data for estimating the vehicle's full throttle performance. The maximum possible energy recovered, stored and deployed by the Energy Recovery System (ERS) was estimated for the first 10 circuits in the 2019 FIA Formula One World Championship ${ }^{\circledR}$ Race Calendar. A 1.6L V6 Internal Combustion Engine (ICE), as well as, a full vehicle was modelled according to the 2019 Federation Internationale de l'Automobile (FIA) Formula One technical regulations using GT-Suite software. The model was validated against the experimental data. The data for validation was extracted from On- Board videos using Optical Character Recognition (OCR) and FIA regulations. Strategy for qualifying has been developed for all 10 circuits and compared. Strategies used by different drivers on different circuits are analysed and the optimum strategy for maximizing the Power Unit's (PU) performance is proposed.
\end{abstract}

Findings show that the data acquired from FIA Formula One on-board videos from the F1 TV App is highly accurate in conjunction to the official lap time with an error of less than $1 \%$. The full car model is able to meet the Target Vehicle Speed at the required gear number and follow the FIA regulations at all times. Factors affecting the performance of the PU such as Average vehicle speed and the Motor Generator Unit-Kinetic (MGU-K) deployment speed have been found and quantified. Driver to Driver variation in the MGU-K deployment speed for maximizing performance during qualification has been quantified. It was found that the winning drivers had higher Average vehicle speed and MGU-K deployment speed which resulted in better performance from the PU. The maximum possible energy recovered per lap by the MGU-K is analysed for both the qualification and race laps. It was found that the energy recovered per lap by the MGU-K is higher in race laps as compared to qualification laps because of increase in the vehicle mass due to fuel weight. Lastly, Strategies have been proposed to maximise the performance of the PU for qualification and race.

\section{Introduction}

Formula 1 (F1), has used a number of different engine rules. The earliest engines used where either a 4.5 Litre Naturally Aspirated (NA) or a 1.5 Litre supercharged (SC) engine with the engine being mounted in the front. The beating heart of a Formula 1 car has been the Internal Combustion Engine (ICE), although today it is a part of a highly complex subsystem known as the Power Unit.
In 2006, FIA introduced new regulations limiting the number of engines per Grand Prix, putting the emphasis on increased reliability. This led the manufacturers to push their engineers to design and develop a fuel-efficient engine for optimum power delivery and increased reliability [1]. In addition, the change from V8 to V6 engines in Formula 1, in 2014, aimed to bridge the link between the passenger vehicles and high-performance motorsport vehicles in the area of fuel efficiency and economy. Stringent regulations were introduced by the FIA to limit the power from ICE, while allowing heat energy from the exhaust and brakes to be recovered, stored and deployed for additional power. The engine was no longer solely responsible for developing power and hence the term Power-Unit (PU) was coined. The Energy Recovery System (ERS) is capable of providing an additional $160 \mathrm{bhp}$ that dramatically increases the PU's overall efficiency [2].

The PU is deemed to consist of six separate elements: the ICE, the motor generator unit-kinetic (MGU-K), the motor generator unit-heat (MGU-H), the energy store (ES), turbocharger (TC) and control electronics (CE) [3]. Engine manufacturers are trying to optimise the energy recovery and deployment strategy in order to maximize the benefits of using two electric motors in the PU subsystem. Although progress has been made in developing a highly efficient PU, the limit to which this system can be pushed to is still unknown due to a significant knowledge gap between the technological choices available and the optimal control strategy used. This highlights the need for intensive research required in the area of ERS within F1 and automotive industry.

With regulations dictating everything in Formula One, it is clear that the technological advancements in the engine and powertrain subsystem has been highly restrictive [4]. The only area for scope of development and progress in technology is the optimisation of ERS. Therefore, engine manufacturers are trying to optimise the energy recovery and deployment strategy in order to maximize the benefits of using two electric motors in the PU subsystem. The MGU-K is fixed rigidly to the transmission before the main clutch. This should be done by using gears of fixed speed ratio which limits the maximum rotational speed of the MGU-K to 50,000 RPM [4]. The primary function of the MGU-K in a Formula One Car is to give additional power to the driveshaft which is limited to a maximum of $120 \mathrm{~kW}$ and maximum torque of $200 \mathrm{Nm}$ (measured at the driveshaft [4]).

The MGU-K also recovers energy during braking by converting the kinetic energy of the vehicle into electric energy which would otherwise get wasted as heat energy. The electromagnets present in the motor resist the rotational inertia of the driveshaft during braking which causes energy to be sapped from the wheels to slow the vehicle and charge the battery. The limitation in this case is that only a maximum $120 \mathrm{~kW}$ of Power can be recovered by the MGU-K. The Energy Flow Chart given in the FIA Technical Regulations [4] also 
states that the MGU-K can provide additional power to both the engine and the ancillary units as long as the total power output does not exceed the limit of $120 \mathrm{~kW}$. The regulations also limit the MGU-K for the maximum energy recovered which is $2 \mathrm{MJ}$ per lap for recovery and maximum energy deployed which is $4 \mathrm{MJ}$ per lap for deployment in terms of giving energy to the battery as well as taking from it.

The MGU-H is the other electric motor which is a part of the ERS configuration. It is used to avoid turbolag at lower engine speeds and recover excess energy at higher engine speeds. It recovers energy from the exhaust gases at higher engine speeds. The regulations limit the maximum rotational speed of the MGU-H to 125,000 RPM. Since the energy transfer between the turbocharger and MGU-H and the MGU$\mathrm{H}$ and the battery is unlimited, this allows for improvisation and optimisation of energy recovery and deployment strategies. This system needs to be optimised to reduce the battery size to the minimum weight of $20 \mathrm{~kg}$ and also provide power on demand at all times.

If the proposed plan for 2021 is to run Power-Units without MGU-H, it will decrease the cost factor and complexity of engine design and increase MGU-K power for overall efficiency and performance of the car. A highly optimised strategy for ERS in F1 will enable the driver to harness the full potential of the PU for maximum performance in terms of power and efficiency.

Optimizing the PU to increase the efficiency of the Powertrain system, is the main challenge for engineers in order to achieve a competitive edge against other rival teams [5]. As imposed by the FIA regulations [4], the maximum fuel flow rate is $100 \mathrm{~kg} / \mathrm{h}$ beyond an engine speed of $10500 \mathrm{rpm}$ and fuel capacity of a maximum of $110 \mathrm{~kg}$ at the start of the race. Also Sporting Regulations state that fuel cannot not be added or removed from a car during a race [6]. It therefore becomes supercritical to manage the energy flow path in the ERS to obtain maximum flow fuel rate which controls the power from ICE: -

$$
\mathrm{P}=\dot{\mathrm{m}}_{\text {fuel }} \times \eta_{\text {thermal }} \times \mathrm{Q}_{\mathrm{HV}}
$$

\section{Data for Modelling the Vehicle}

This work primarily emphasizes on 2019 technical regulation to propose the direction of the industry for 2021. Analysing the regulations from 2017, 2018 and 2019, it was found that there were two components that were to undergo a major change in these years. One was increasing the compression ratio of the ICE from 15 in 2016 to 18 and the other one was complex and complicated aerodynamics change along with the tyres used. Since all the other parameters of the ICE are the same since 2014, the values for the engine following the 2014 technical regulations were available by Tom Kempynck [7].

A 2019 F1 chassis was developed by Perrinn [8] and the information regarding tyres can be found in the FIA technical regulations as the tyres need to obey the regulations. Assuming the calorific value of $44,600 \mathrm{~kJ} / \mathrm{kg}$ [9] and brake horse power of the current PUs from the literature [10], the brake thermal efficiency of the engine can be estimated to set the target for peak power of the V6 model. The data also helps to validate and verify the model. Using Computational Fluid Dynamics (CFD) simulations on the F1 model developed by Perrin the coefficient of drag and lift were found. The effect of gravity on change in circumference of tyres under loaded conditions was found in [11]. The V6 engine was modelled using a steady state map-based model approach. The modelling was done in GT-Power and the engine was calibrated to meet the fuel flow and the maximum power.

The full car model is then developed in GT- Drive which meets all the FIA Technical and sporting regulations. The other elements of the PU like the MGU-K, the MGU-H and the energy store (ES) have been modelled using the FIA technical regulation data. The Control Electronics (CE) have been defined in GT-Suite, in order to follow the FIA energy flow chart [4]. Driver data for the first 10 circuits has been obtained by extracting information from on-board videos from the F1 TV App [12]. The 2019 Pole Position Lap at the Australian GP is used to validate the model.

\section{Modelling Methodology}

The methodology was divided into two parts: experimental and numerical. In the experimental method, data was analysed and extracted from the FIA Formula One on-board videos from the F1 TV App along with analysis of lap time, pit stop times, pit stop strategy used, driver to driver lap time variation. In the numerical method, a fully regulation compliant V6 engine model and full car model was built using all the data available from literature and published content. The regulations [4] dictate that the maximum possible energy depletion from the battery cannot be more than $4 \mathrm{MJ}$ at any point of time. This means that if the MGU-K is able to recover $2 \mathrm{MJ}$ of energy while deploying $4 \mathrm{MJ}$ of energy, effectively the system can deploy $6 \mathrm{MJ}$ of energy in total for increased performance while still being within regulations.

\section{Formula One V6 Engine model development}

Since the Engines in Formula One are Fuel Flow restricted, this parameter was chosen as the starting point to reconstruct the overall power output of the engine as the fuel flow rate curve is specified in the FIA Technical Regulations [4]: -

$$
\dot{\mathrm{m}}_{\text {fuel }}=0.009 \times \mathrm{RPM}_{\mathrm{ICE}}+5.5\left(\frac{\mathrm{kg}}{\mathrm{hr}}\right) \mathrm{RPM}_{\mathrm{ICE}}<10500
$$

$$
\dot{\mathrm{m}}_{\text {fuel }}=100\left(\frac{\mathrm{kg}}{\mathrm{hr}}\right) \mathrm{RPM}_{\mathrm{ICE}}>10500
$$

The mass flow rate of air is determined using the equation below where 14.72 is the stochiometric ratio for gasoline. It was chosen to use lambda $(\lambda)=1$ for balancing the vehicle's performance as well as the fuel efficiency [12]:

$$
\begin{gathered}
\dot{\mathrm{m}}_{\text {air }}=\lambda \times 14.72 \times \dot{\mathrm{m}}_{\text {fuel }} \\
\lambda=\frac{\left(\dot{\mathrm{m}}_{\text {air }} / \dot{\mathrm{m}}_{\text {fuel }}\right)_{\text {actual }}}{\left(\dot{\mathrm{m}}_{\text {air }} / \dot{\mathrm{m}}_{\text {fuel }}\right)_{\text {stochiometric }}}
\end{gathered}
$$


The total mass flow rate is estimated by adding the mass flow rate of air and the mass flow rate of fuel.

$$
\dot{\mathrm{m}}_{\text {total }}=\dot{\mathrm{m}}_{\text {air }}+\dot{\mathrm{m}}_{\text {fuel }}
$$

The theoretical mass flow rate of air through an engine can be calculated based on equation (7):

$$
\dot{\mathrm{m}}_{\text {air }, \mathrm{NA}}=\mathrm{n}_{\text {open, cylinders }} \times \frac{\mathrm{V}_{\text {ICE }}}{\mathrm{n}_{\text {cylinders }}} \times \eta_{\text {vol }} \times \rho_{\text {air }} \times \frac{\mathrm{RPM}_{\text {ICE }}}{n_{\text {rev per intake }} \times 60}
$$

The information regarding compressor and turbine maps were extracted using image to data software [14], and fed into the compressor and turbine maps in the 1D simulation model in GT-Power. The cylinder geometry was calculated using data specified in the FIA technical regulations which states a bore size of $80 \mathrm{~mm}$ and compression ratio of 18 . The stroke was determined using the swept volume and bore details.

Intake and exhaust valve diameters were estimated from the data set which contains component dimensions for 50 historical F1 engines [15].

The V6 engine was modelled in GT-Power along with the turbocharger and waste gate. A Proportional Integral Derivative (PID) controller was used to regulate the turbine waste gate to achieve the specified fuel flow rate for each RPM for an average of 20 engine cycles.

The MGU-H is connected to the turbocharger through a fixed gear ratio as stated in the FIA Technical Regulations [4] and the power deployed and recovered by it is estimated. The waste gate is fully closed and the V6 engine model is evaluated. Since not all the energy excess energy present in the exhaust gases can be recovered by the MGU-K, it is assumed that the difference in energy between a fully closed waste gate turbocharger and a PID controlled waste gate, on the turbine side would be the recovered energy by the MGU-H. The power recovered by the MGU-H can be calculated by multiplying this energy difference with the required rotational speed of the turbocharger to meet the fuel flow rate limit.

$\mathrm{P}_{\mathrm{MGU}-\mathrm{H}, \text { Recovery }}=\left(\mathrm{E}_{\text {turbine, closed WG }}-\mathrm{E}_{\text {turbine, PID }}\right) \times \omega_{\text {shaft required to meet }} \dot{\mathrm{m}}_{\text {fuel }}$

At lower engine speeds, the exhaust gasses do not contain sufficient amount of energy to spool the compressor. Therefore, the power required to spool the compressor is to be deployed by the MGU-H. Thus, the turbine and compressor need to be split. In order to control the speed of the compressor, a speed-controlled shaft is used. The Fuel flow rate dictates the speed of this shaft and this is controlled by using a PID controller. In order to obey the Fuel Flow rate restrictions, set by the Technical Regulations [4] and to maintain lambda $(\lambda)=1$, the total amount of air that needs to be compressed and the Energy required by the compressor to compress this amount of air is obtained. The power needed by the MGU-H to spool the compressor is calculated using the same format of equation above:
$\mathrm{P}_{\mathrm{MGU}-\mathrm{H}, \text { Deployment }}=\left(\mathrm{E}_{\text {compressor, controlled shaft }}-\mathrm{E}_{\text {compressor, PID }}\right) \times \ldots$.

$\times \omega_{\text {shaft required to meet } \dot{\mathrm{m}}_{\text {fuel }}}$

(9)

\section{Data Extraction using Optical Character Recognition}

The on-board telemetry gave information about three valuable datasets namely Vehicle Speed, Engine Speed and Gear Number. Videos were recorded of the fastest lap during qualification and all the laps during the race of all the drivers who successfully finished the race [16].

This data was then processed in MATLAB [17]. The videos were then converted to frames to increase the accuracy of results. Taking inference from legislative drive cycles used for automotive testing, the time interval chosen to extract and plot data was set to one second. Based on the frame rate of video recording and the lap time published on the FIA website, the required frames from plotting the data were separated out from rest of the frames.

Using Optical Character Recognition (OCR) from the vision toolbox, the datapoints corresponding to Vehicle Speed, Engine Speed and Gear Number were extracted from the required frames [18] [19]. This data was them written to an excel spreadsheet wherein the plots of Vehicle Speed v/s Time, Engine Speed v/s Time, Gear Number v/s Time and Distance Travelled v/s Time were developed. The videos were also used to analyse the gear shift speeds of all the drivers for all the races to get an idea of shift strategy deployed by different drivers and different teams according to the vehicle and PU configuration. The Vehicle Speed v/s Time plot was used as a Target Vehicle Speed plot for the full vehicle model of the Formula One car modelled in GTDrive.

A comparative analysis was done for the fastest laps in qualification between the driver winning the pole position for race, the drivers who finished the race in 1st Place, 10th Place and the last driver to successfully complete the race. Since the time interval selected was one second, the Vehicle Speed v/s Time trace could be easily converted to Vehicle Speed v/s Distance. This was done for ease of data analysis due to the fact that the total distance of the track remains fixed and the start point and end point of a lap is known. In-order to get the shift speed data, a video from start of the race is analysed as in-order to get the best start and maximum speed and acceleration, the vehicle is driven at full throttle. This is plotted for all the four drivers mentioned above to analyse the shift strategy used by drivers and to evaluate the transmission ratio $\left(i_{o} i_{\theta}\right)$ of the cars since the relationship between Vehicle Speed, Engine Speed, Tyre Radius and Transmission Ratio is:

$$
\omega_{\text {engine }}=i_{o} i_{\theta} \frac{V_{\text {vehicle }}}{r_{\text {tyre }}}
$$

\section{Development of Full Car model and controls to implement strategy}

The values of Power recovered and deployed by the MGU-H are taken from the 2D map that was created and this is then converted into a look up table. The Brake Mean Effective Pressure (BMEP) values for all RPM and throttle positions that is developed in the engine is extracted 


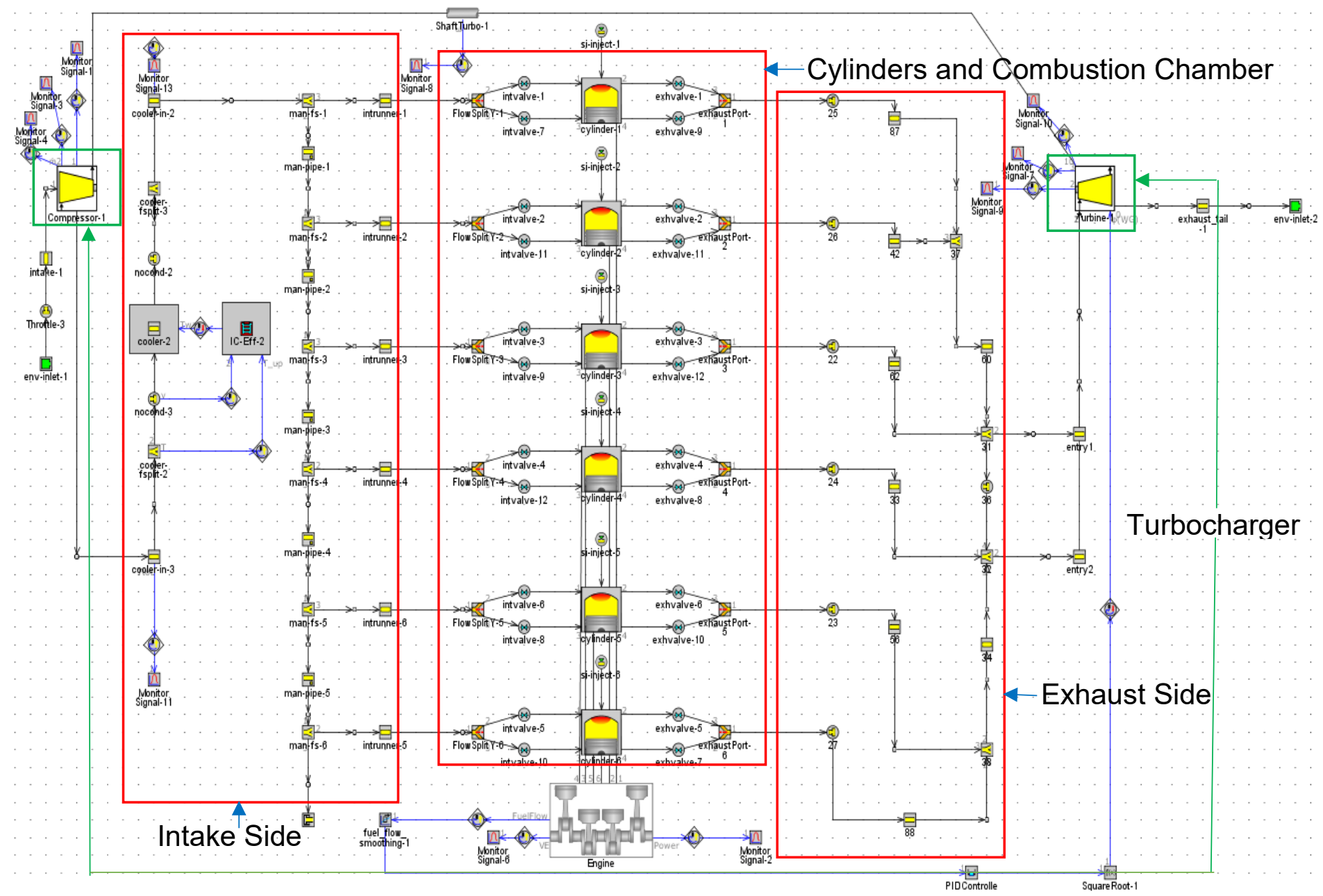

Figure 1. Representative V6 Engine Model Compliant to FIA 2019 Regulations modelled in GT-Power

from the V6 Engine Simulation. This is then fed as an input to a steady state ICE model within the full car model in GT-Drive.

The force required to drive the vehicle is calculated from the equation:

$$
\begin{aligned}
\mathrm{F}_{\text {tractive }}=\mathrm{mgsin}(\alpha)+ & \left(\frac{1}{2} \times \rho_{\text {air }} \times \mathrm{A}_{\text {frontal }} \times \mathrm{V}^{2} \times \mathrm{c}_{\mathrm{d}}\right)+\ldots \ldots \\
& +\mathrm{c}_{\mathrm{r}}\left[\left(\frac{1}{2} \times \rho_{\text {air }} \times \mathrm{A}_{\text {frontal }} \times \mathrm{V}^{2} \times-\mathrm{c}_{\mathrm{L}}\right)+\operatorname{mgcos}(\alpha)\right]
\end{aligned}
$$

The diameter of the whole wheel can be a maximum of $670 \mathrm{~mm}$ when fitted by dry tyres as stated in the FIA Technical Regulations [4]. Taking $1 \%$ decrease in the tyre's circumference [12] when the tyre is loaded on the ground and also the proportionality that circumference is directly related to wheel diameter, the tyre's corrected diameter was found to be $663 \mathrm{~mm}$ (99\% of 670). Thus, in order to drive the vehicle, the total torque required is calculated by:

$$
\mathrm{T}_{\text {tractive }}=\mathrm{F}_{\text {tractive }} \times \mathrm{r}_{\text {wheel,corrected }}
$$

Using CFD simulations on the F1 model developed by Perrin [8] the coefficient of drag and lift were found. From the onboard telemetric data, all the shift speeds of all the drivers was analysed and the information regarding top speed attained by each vehicle was taken from published FIA results [20]. The force required to drive the vehicle considering zero elevation is calculated using the simplified equation:

$$
\begin{aligned}
\mathrm{F}_{\text {tractive }}=\left(\frac{1}{2} \times \rho_{\text {air }} \times\right. & \left.\mathrm{A}_{\text {frontal }} \times \mathrm{V}^{2} \times \mathrm{C}_{\mathrm{d}}\right)+\ldots \\
& +\mathrm{C}_{\mathrm{r}}\left[\left(\frac{1}{2} \times \rho_{\text {air }} \times \mathrm{A}_{\text {frontal }} \times \mathrm{V}^{2} \times-\mathrm{C}_{\mathrm{L}}\right)+1\right]
\end{aligned}
$$

The value of under gearing ratio was found to be 1.1 as the maximum vehicle speed was occurring at an engine speed of 11500 RPM from the on-board data while the peak power of the engine was occurring at 10500RPM. The engine peak power was validated from the FIA Technical Regulations [4] which say that the Fuel Flow is capped off beyond 10500 RPM. The value of Final Drive ratio was chosen as 1.1 because the engine speed and driveline speed are almost the same at the Vehicle's Top Speed.

Modelling of the MGU-K is shown in Figure 2. The data for the efficiency of the motor-generator unit was taken from Toyota Prius GT-Suite model. Since the FIA Technical Regulations [4] restrict the 
maximum rotational speed of the MGU-K to 50,000 RPM and the maximum power output and torque output to $120 \mathrm{~kW}$ and $200 \mathrm{Nm}$ respectively, the maps used in the Toyota Prius GT-Suite model is scaled accordingly. The torque output from the MGU-K is calculated using: -

$$
\mathrm{T}=\frac{\mathrm{P} \times 60}{2 \pi}
$$

The power values taken into consideration for estimating minimum and maximum torque is dictated by the FIA Technical Regulations [4] which states $-120 \mathrm{~kW}$ for recovery and a maximum $120 \mathrm{~kW}$ for deployment. The regulations also state that the MGU-K should be permanently and mechanically fixed to the transmission before the main clutch using gears of fixed speed ratio. Taking into account the ratio between maximum rotational speed of the MGU-K allowed and the maximum rotational speed of the ICE allowed, the initial fixed speed ratio chosen was 3.33. Integrators were used in this section to determine the total energy recovered and deployed by the MGU-K depending on whether the power demand to the MGU-K is positive or negative.

The decision for battery sizing initially was taken from Bengolea and Samuel [21], the best choice a target State of Charge (SOC) of 0.8 was chosen for the simulation. For Race Strategy the target SOC for best performance was set to 0.8 and for Qualification it was set to 1 .

Since a steady state model of the ICE is used, the modelling of the MGU-H is done using 2D lookup tables. Figure 3 illustrates the modelling of MGU-H done in GT-Drive. There are two input signals
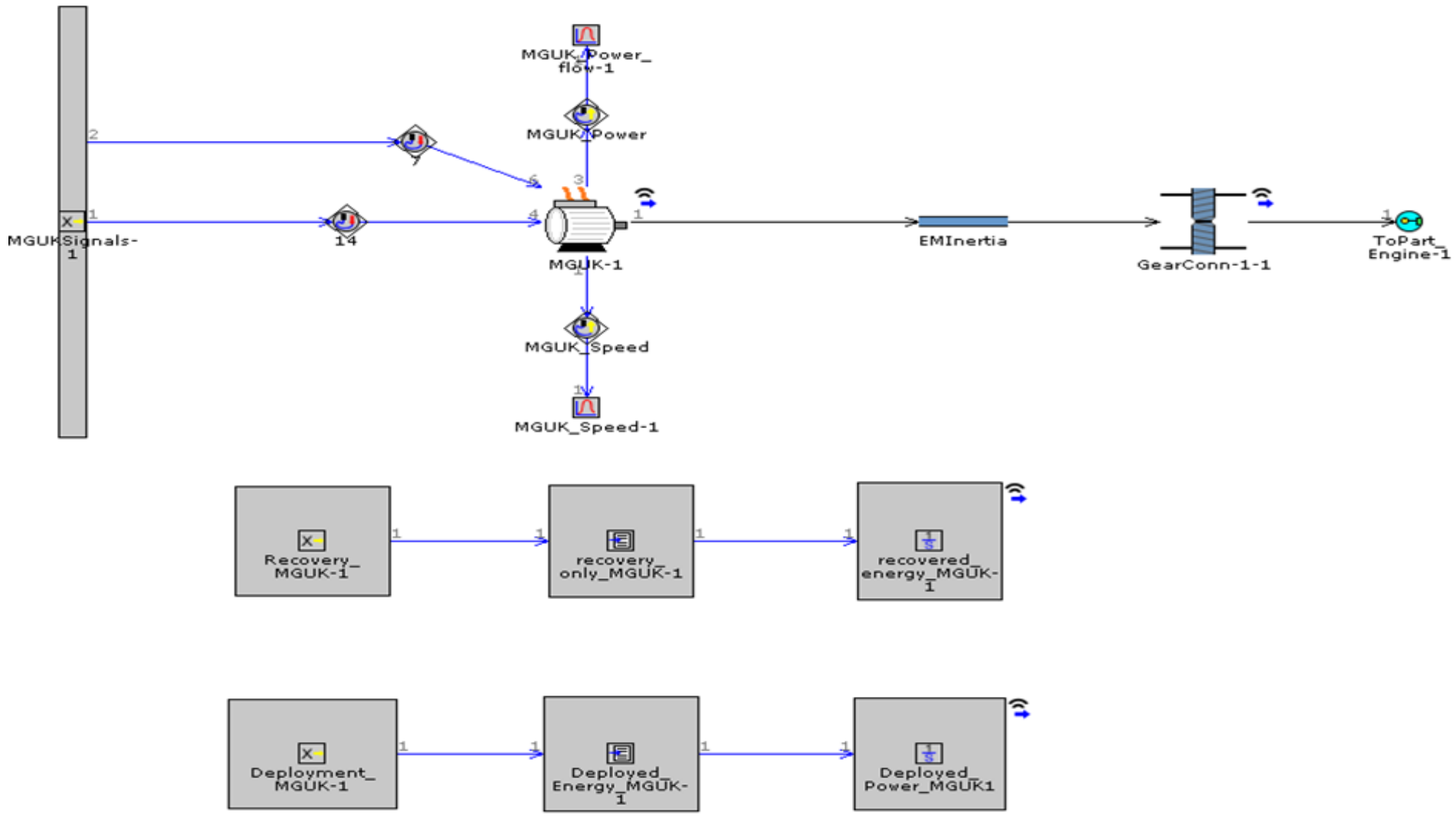

Figure 2. Modelling of the MGU-K mechanically linked to the engine crankshaft used in this case namely Engine speed and Throttle position. The values of Power deployed and recovered by the MGU-H as well as the turbine shaft speed that is obtained from the V6 Engine Simulation is fed as a 2D lookup table which can be found in the "MGUH Power1" and "MGUH_speed-1" blocks. As the FIA Technical Regulations [4]. limit the maximum rotational speed of the MGU-H to 125,000 RPM, there is a fixed gear ratio used, which is represented by a gain object. The efficiency of the MGU-H and the torque generated is determined using the speed and power output values from the "MGUH Power-1" and "MGUH speed-1" blocks.

The power request from the MGU-H in the sub-system is realized by using a switch on the far right. Based on whether the MGU-H is recovering or deploying energy, the switch logic gate decides what to the Battery, MGU-K and Control Electronics. Since the proposed regulations for 2021 hint towards the removal of MGU-H [22], gain blocks are introduced before the switch block. This is done in order to remove the power recovery and deployed options from the MGU-H side to evaluate the maximum performance envelope of the PU with only the MGU-K.

\section{Design of MGU-K Control Strategy for 2019 Regulations}

In order to control and limit the energy flow through the MGU-K, a controller was designed to follow 2019 FIA regulations. As the energy flow through the MGU-K is highly restricted as per the regulations, in order to clearly manage the energy flow path, this controller has been split into three sections as illustrated by Figure 4. would be the appropriate power demand/recovery values to send across 

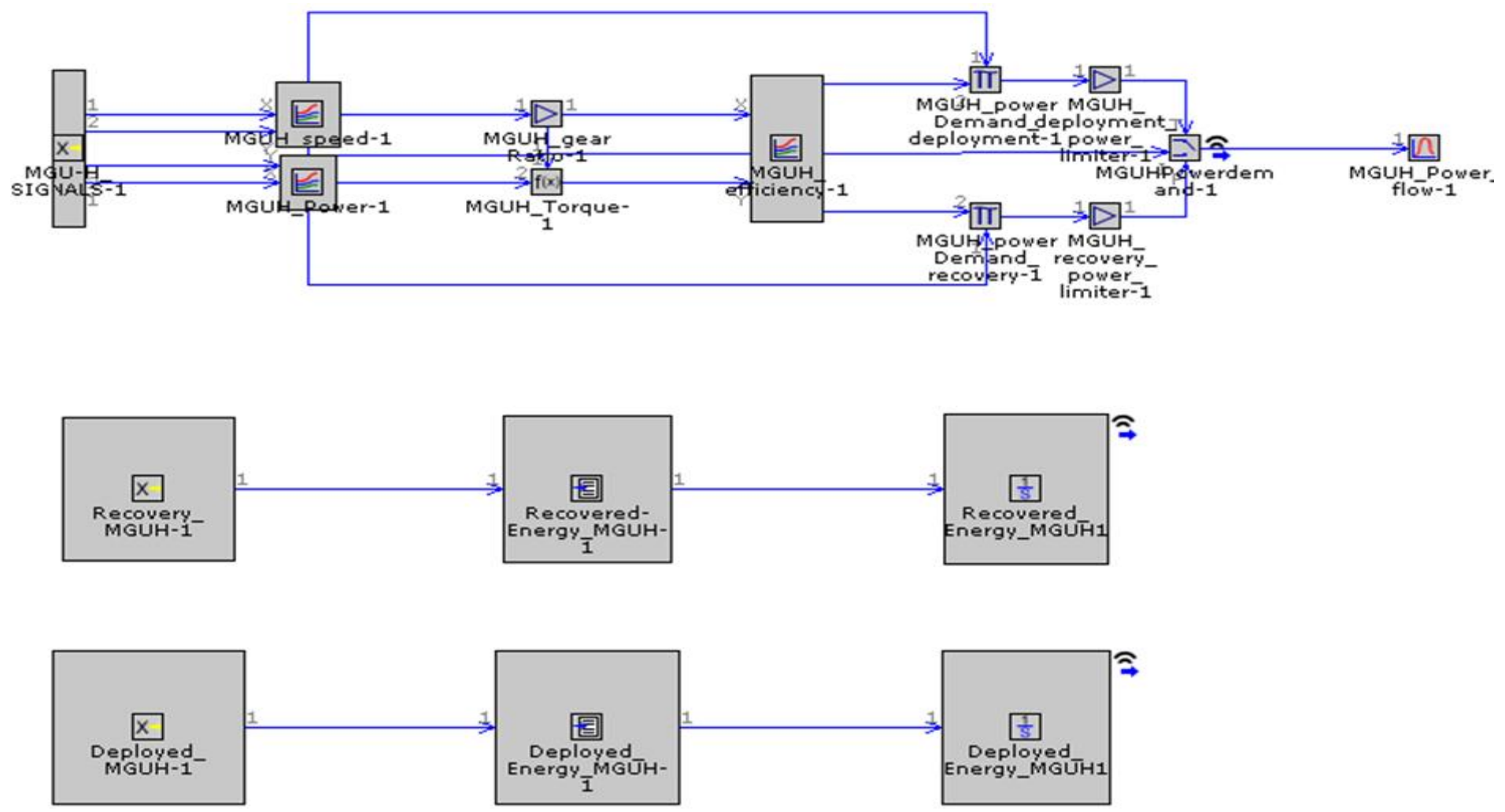

Figure 3. Modelling of MGU-H power from data obtained from V6 Engine Simulation

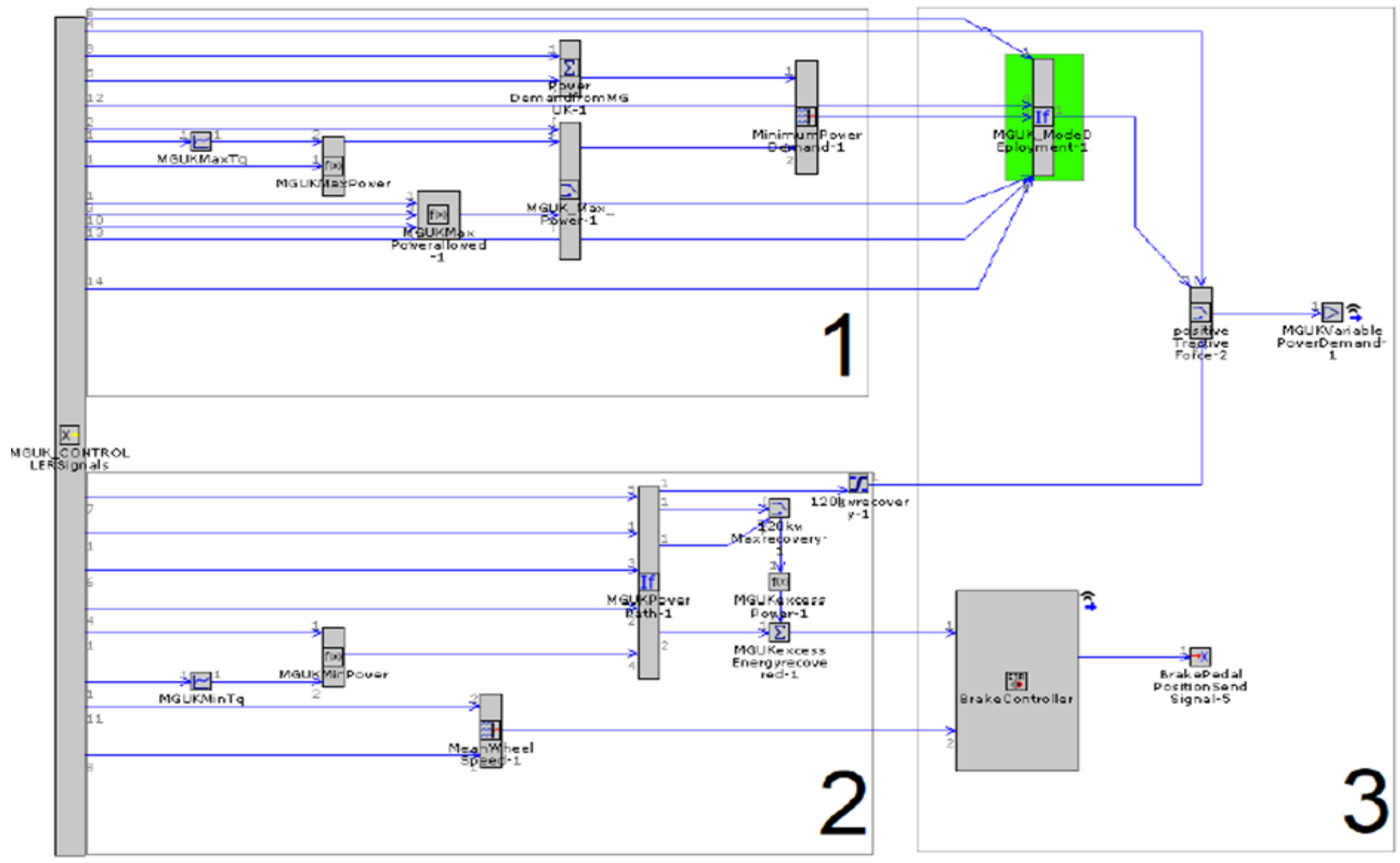

Figure 4. Modelling of MGU-K power deployment and recovery controller

Page 6 of 16 
Section 1 in Figure 4 deals with the implementation of a series of calculations and logic gates. The control logic used in this section is specifically for the power deployment side of the MGU-K. The maximum power that is available from the engine at the current RPM is calculated along with the maximum power for the $200 \mathrm{Nm}$ torque to be applied to the crankshaft. Lastly, for the vehicle to achieve the targeted speed, the minimum energy demand required from the MGU$\mathrm{K}$ is also calculated. A comparison is done between the maximum power available and the maximum power associated to the crankshaft torque. The power required to meet the target speed is then compared to this value, and the smaller of the two inputs is then selected.

Section 2 in Figure 4 deals with the power recovery side of the MGU$\mathrm{K}$ as a series of calculations and logic gates. Taking information from the rotational speed of the MGU-K and the torque map constructed for recovery, the minimum power available is calculated. A logic gate is put forth which takes the input signal of minimum power and depending on the torque demand, it decides whether to apply pure regenerative braking or pure friction braking or a combination of both. Pure regenerative braking is only used if the Braking force corresponds to a maximum value of $120 \mathrm{~kW}$. If frictional brakes are used, then average speed of the two driven wheels and the braking force required is transferred to the brake controller. Based on the inputs to the brake controller, the torque applied to the brake discs is adjusted in order to slow the car.

Section 3 in Figure 4 of the controller, based on the engine mode (qualifying and race) determines the power deployed using a logic gate. Different strategies have been created for the two engine modes. The race strategy is aimed for a targeted SOC of 0.8 , and the maximum available power will always be deployed if the current SOC is 0.4 or larger and the vehicle speed is greater than the MGU-K Deployment Speed. The MGU-K Deployment Speed is a parametric variable which can be placed by the user to determine the maximum power deployed, the duration for which it is deployed and the maximum energy used. This also uses the inputs from the total energy already recovered and deployed from the MGU-K (used from the battery) to determine the demand power to make sure that this sub-system always follows the FIA Technical Regulations. If the vehicle speed is less than the deployment speed or the SOC is below 0.4 , there would be no power demanded from the MGU-K.

From the calculations of Section 1 and Section 2, the amount of power available for deployment and power available for recovery are transmitted to a logic gate. Based on the tractive power demand by the driver to attain the target vehicle speed, the gate decides whether the MGU-K should deploy or recovery energy. If the torque demand is negative then power recovery is possible and this is requested by the MGU-K and if the torque demand is positive, then power deployment is requested by the MGU-K. The Electrical Power required by the MGU-K to match the power demand is then calculated and transmitted to the Energy Store Controller.

\section{Design of Energy Storage Controller for 2019 regulations}

An energy store controller is modelled to maintain, limit and regulate the power demand from the two MGUs in terms of energy transfer between the battery and the motors. Calculations were done in order to determine the energy that can be transferred between the two motors as this greatly helps to apply the restrictions imposed by the regulations. Although this increases the complexity of the controller, it makes sure that the sub-system is always compliant to the FIA Technical Regulations and makes sure that the car is legal to run.

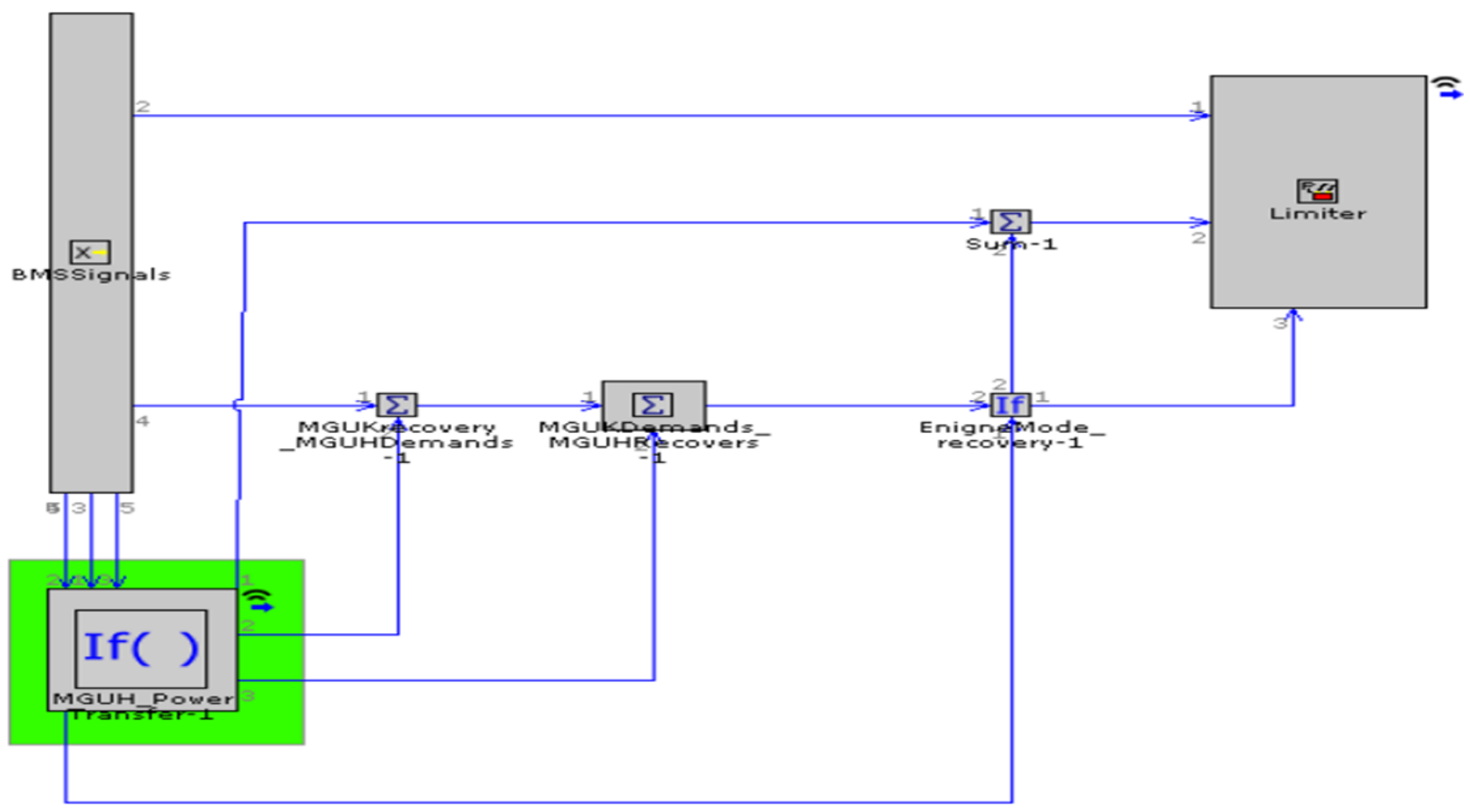

Figure 5. Modelling of Energy Storage controller 
Figure 5 highlights the energy flow through the PU. The energy flow from and to the MGU-H is converted into a simple logic case and highlighted in green as the "MGUH PowerTransfer-1" block. This is comparable to the control logic used to determine the power demand and request from the MGU-K modelled in the MGU-K controller. The logic case takes inputs from the power demand and request from both the MGU-K and MGU-H and consists of multiple if else statements. This is used to estimate the energy that is transferable between the two MGUs depending on the current mode of operation of the two (recovering power, deploying power and if extra amount of power is required).

This block then decides power that needs to be demanded by the MGU$\mathrm{H}$ from the battery. The next step is modelling the energy transfer between the two Motor Generator Units, where power is demanded for recovery and deployment through the battery and is routed partly from the MGU-H and completely through the MGU-K based on the engine mode. The control logic is designed in such a way that it allows for energy transfer between the MGU-K and the battery to be within the limits specified by the regulations at all times.

\section{Model Validation}

\section{Validating the V6 Engine Model}

The V6 engine model is run for the range of 4000 RPM to 15000 RPM with increments of 500 RPM. The throttle positions are also changed for each RPM case ranging from 0 to $100 \%$ with $10 \%$ increase. It is assumed that by decreasing the throttle by $10 \%$, it would result in a $10 \%$ area decrease for the air intake. A linear relationship can be established between throttle position and mass flow rate of fuel as the mass flow rate of air is directly related to the area, which in turn dictates the mass flow rate of fuel.

The PID controllers for the MGU-H deployment and recovery power is tuned over a number of simulations to make sure that the fuel flow is maintained within the regulations at all times and the power developed by the engine alone is close to $790-840 \mathrm{hp}$.

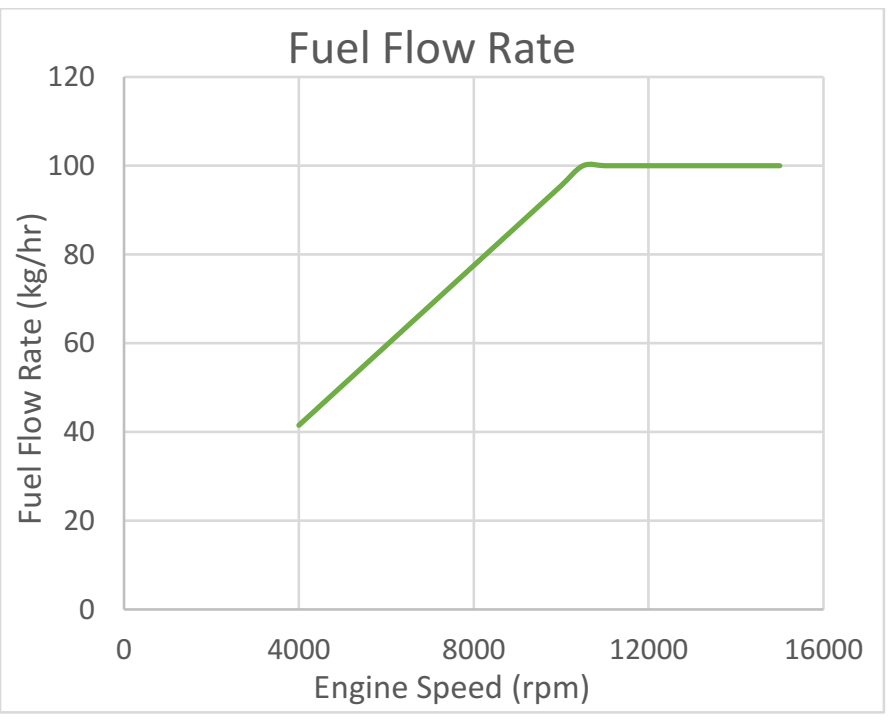

Figure 6. Fuel Flow Rate Plot as per FIA technical regulations [9]

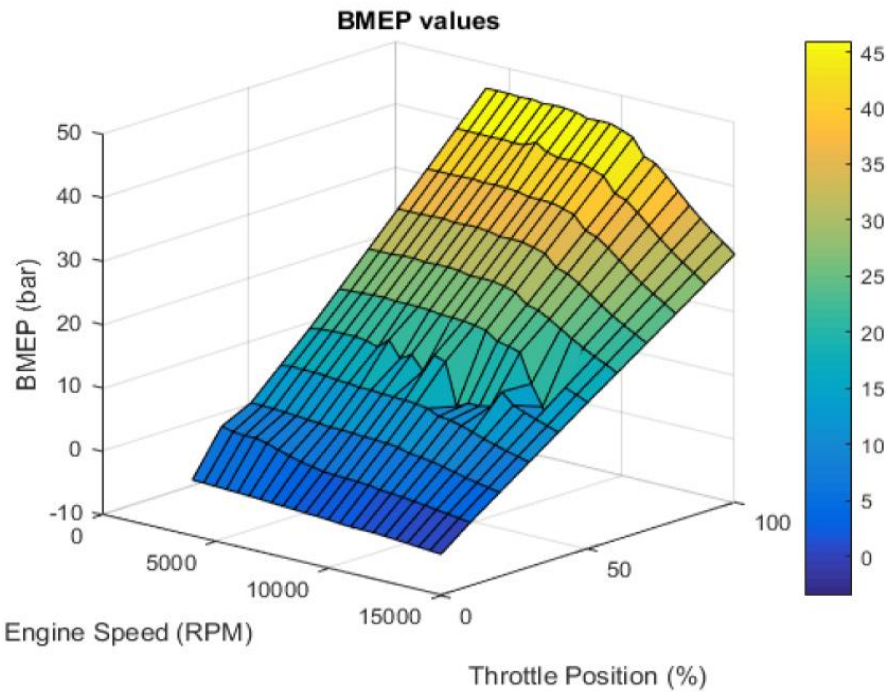

Figure 7. BMEP Surface Plot of the ICE as a function of Engine Speed and Throttle Position

Figure 7 shows the Brake Mean Effective Pressure (BMEP) plot of the ICE from the simulation of the V6 Engine Model. The results show that the engine follows an expected trend which depicts a drop in BMEP after 10500 RPM due to the fuel flow being capped off.

Figure 8 shows MGU-H demand and recovered powered from the V6 engine simulation results. It can be seen that the MGU-H only requests power from the ERS to keep the turbocharger spooling at lower engine speeds and higher throttle positions. Other than that, the MGU-H always recovers power.

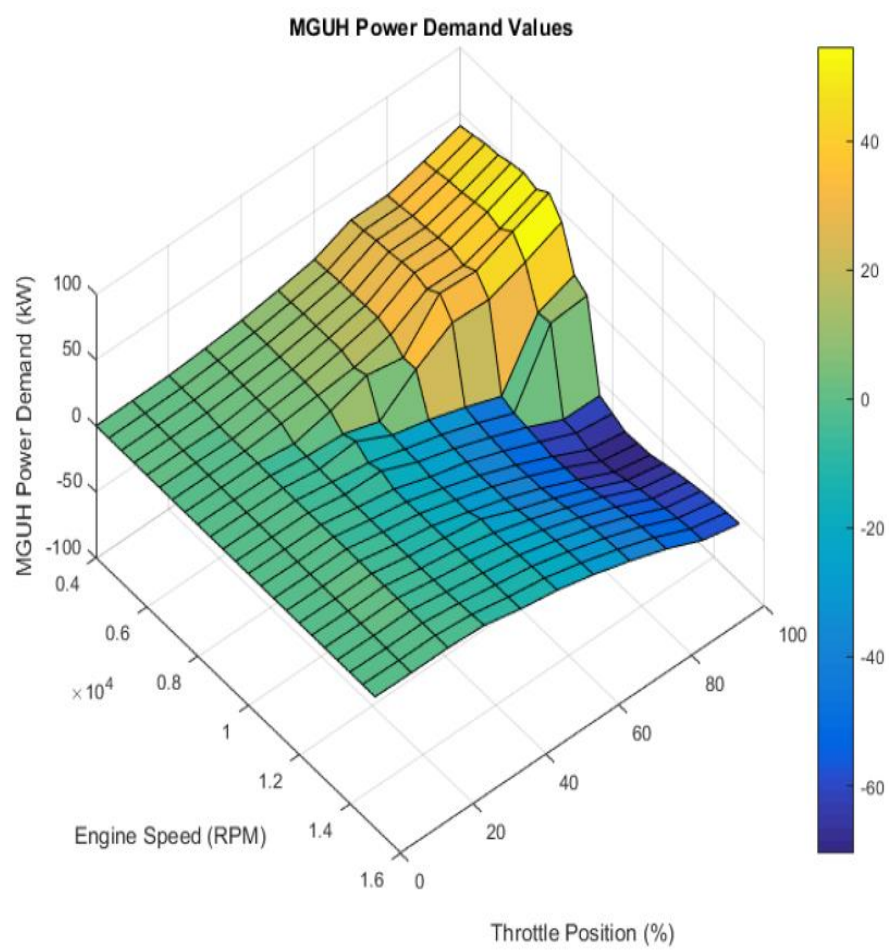

Figure 8. MGU-H power demand plot as a function of Engine Speed and Throttle Position 
Validating the Full Car Model

The data from the V6 Engine simulation is fed in the full car model along with the Target Vehicle Speed to be followed by the car (extracted from on-board data). The gear ratios that were calculated from the on-board video data is also fed as input to the gearbox inorder to make sure that the car follows the Target Vehicle Speed at the Target Gear Number. The model is then run and validated against Pole Position Lap at the Australian GP 2019.

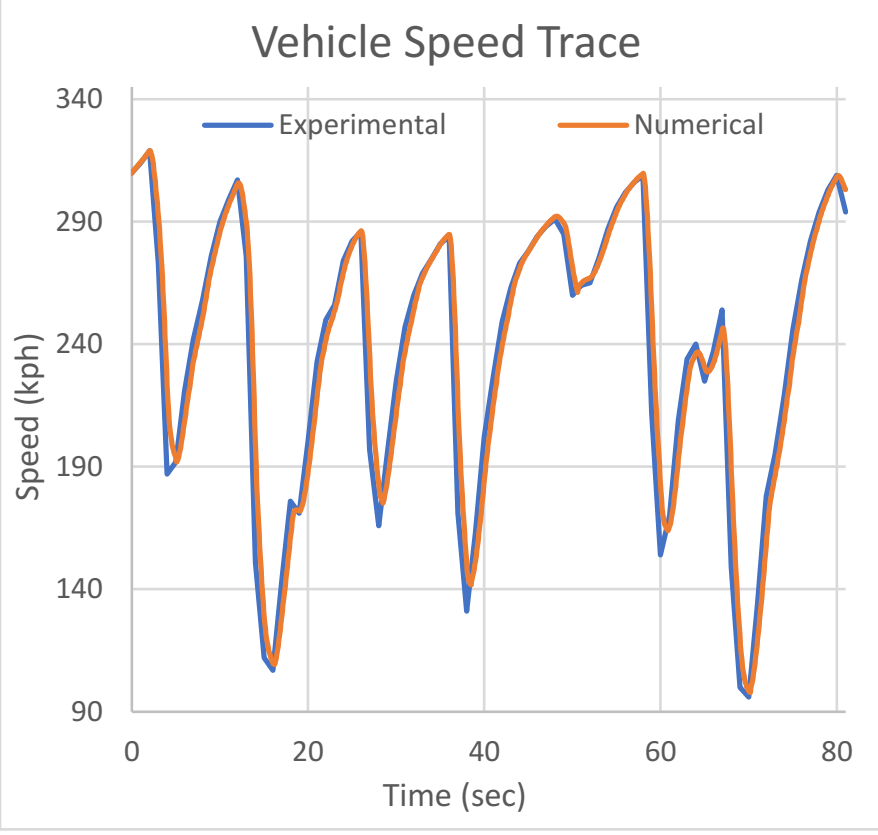

Figure 9. Vehicle Speed Comparison Plot Experimental v/s Numerical Data

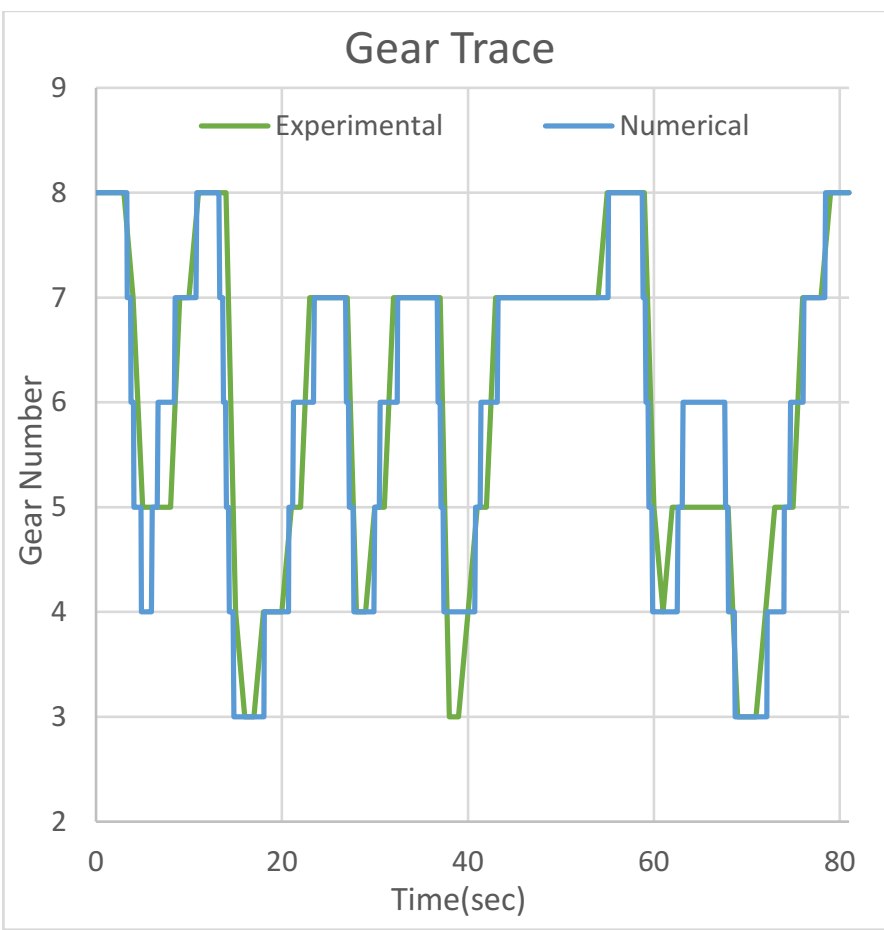

Figure 10. Gear Trace Comparison Plot Experimental v/s Numerical Data
Table 1. Comparative Analysis of Total Distance Travelled and Error \%

\begin{tabular}{|l|r|}
\hline Driver & Pole Position \\
\hline Circuit & Australian GP \\
\hline Qualification Time & $1: 20.486$ \\
\hline Actual Distance (m) & 5303 \\
\hline Experimental (m) & 5284 \\
\hline Numerical (m) & 5279 \\
\hline Error Experimental (\%) & 0.35 \\
\hline Error Numerical (\%) & 0.45 \\
\hline
\end{tabular}

Figures 9 and 10 show a very good correlation between experimental data extracted from on-board videos and the simulated results using the full car model. The transmission ratios calculated from data extracted at race start gives an insight into the car-setup for different tracks for different drivers. Figure 11 shows the car-setup for Pole Position driver of Australian GP 2019 for the first 5 circuits.

After suitable number of simulations and iterations, the best battery pack sizing which allowed for $120 \mathrm{~kW}$ of power recovery and deployment from the MGU-K was found to be 20 cells in series and 5 stacks in parallel of 20A-h capacity and the fixed gear ratio between the MGU-K and the engine crankshaft was changed to 4 . The model is now validated and meets all the regulations imposed by the FIA technical and sporting regulations to the power-unit subsystem. As the car is now compliant to the 2019 FIA regulations, there are suitable changes made to the energy storage controller to remove the energy transfer from the MGU-H to the MGU-K and the battery as the plan for 2021 is to remove the MGU-H. The energy transfer will occur only between the MGU-K and battery in order to meet the Target Vehicle Speed.

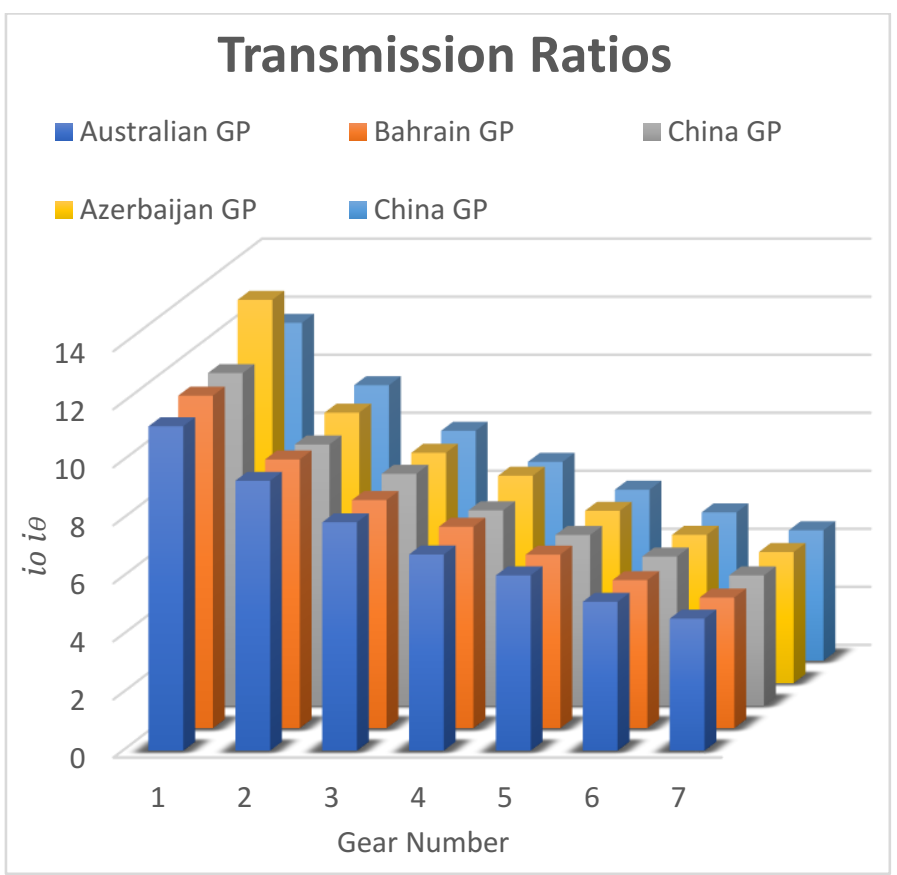

Figure 11. Transmission Ratio Comparison of Pole Position driver of Australian GP 2019

Page 9 of 16 
The modified Full Car model for the proposed 2021 regulations is revalidated against Pole Position Lap at Australian GP 2019 to make sure it follows all the regulations. Once this is done, the model is run for performance analysis of three drivers (Race Winner, 10th Place driver and Race Finisher on last position) for the first 10 circuits in the 2019 FIA Formula One World Championship ${ }^{\circledR}$ Race Calendar.

\section{Strategy Development}

The full vehicle model was simulated for 10 circuits for 3 different drivers which produced a large amount of data. A comparative analysis between total energy recovered, stored and deployed throughout the race as well as qualification is carried out. Emphasis is also given to quantify the maximum possible energy that can be stored, recovered and deployed for each of the three drivers for all the 10 circuits. This is done to quantitively compare the capabilities of different PowerUnits in terms of ERS strategies employed. Effect of removal of MGU$\mathrm{H}$ is carried out to determine the maximum power that can be deployed and recovered from the MGU-K alone (in terms of energy recovered and deployed). The driver data displayed below is in the order of their race positions (Race Winner, 10th Place driver and Race Finisher on last position).

\section{Strategy for Qualification}

The car is lightest during qualification with fuel weight enough for two laps of the circuit (one outlap and one qualification lap). This is done to maximize the top speed and acceleration capabilities of the car. An assumption is taken that the driver deploys and recovers maximum possible energy from the MGU-K in order to clock the best lap.

A comparative analysis of ERS was carried out considering only deployment from the MGU-K side with no recovery and energy recovery + deployment from the MGU-K keeping the battery SOC maximum at the lap start. This is done for estimating the optimal battery pack sizing, weight and initial SOC values for qualification. The tracks that were analysed are listed below in Table 2 .

Table 2. Circuit Characteristics and Information

\begin{tabular}{|l|r|r|r|}
\hline Grand Prix (GP) & Lap Distance (km) & Number of Laps & Total Distance (km) \\
\hline Australian GP & 5.30 & 58 & 57 \\
\hline Bahrain GP & 5.41 & 567.57 \\
\hline Chinese GP & 5.45 & 308.24 \\
\hline Azerbaijan GP & 6.00 & 305.07 \\
\hline Spanish GP & 4.66 & 36 & 306.05 \\
\hline Monaco GP & 3.34 & 78 & \\
\hline Canadian GP & 4.36 & 307.10 \\
\hline French GP & 5.84 & 260.29 \\
\hline Austrian GP & 4.32 & 305.27 \\
\hline British GP & 5.89 & 53 & \\
\hline
\end{tabular}

Table 3. Comparative Analysis of Qualifying Data of Drivers for 2019 season where the average vehicle speed is obtained using OCR and the other data is obtained from numerical simulations

\begin{tabular}{|c|c|c|c|c|c|c|c|}
\hline Driver & $\begin{array}{c}\text { Average } \\
\text { Speed (kph) }\end{array}$ & $\begin{array}{c}\text { MGU-K } \\
\text { Deployment } \\
\text { Speed (kph) }\end{array}$ & $\begin{array}{c}\text { Energy } \\
\text { Deployed } \\
\text { MGU-K Only } \\
\text { (MJ) }\end{array}$ & $\begin{array}{c}\text { MGU-K } \\
\text { Deployment } \\
\text { Speed (kph) }\end{array}$ & $\begin{array}{c}\text { Energy } \\
\text { Deployed } \\
\text { MGU-K Only } \\
\text { (MJ) }\end{array}$ & $\begin{array}{c}\text { Energy } \\
\text { Recovered } \\
\text { MGU-K Only } \\
\text { (MJ) }\end{array}$ & $\begin{array}{c}\text { Maximum } \\
\text { Possible Energy } \\
\text { Recovered } \\
\text { (MGU-K) (MJ) }\end{array}$ \\
\hline & \multicolumn{3}{|c|}{ Deployment Only } & \multicolumn{3}{|c|}{ Deployment and Recovery } & \\
\hline \multicolumn{8}{|c|}{ Australian GP } \\
\hline Pole Position & 237.5 & 257 & 3.98 & 204 & 5.98 & 1.99 & 1.99 \\
\hline $1^{\text {st }}$ Place & 237.0 & 254 & 3.96 & 201 & 5.96 & 2.00 & 2.12 \\
\hline $10^{\text {th }}$ Place & 231.1 & 252 & 3.96 & 202 & 5.96 & 2.00 & 2.20 \\
\hline Last Place & 222.3 & 244 & 3.86 & 195 & 5.86 & 2.00 & 2.38 \\
\hline \multicolumn{8}{|c|}{ Bahrain GP } \\
\hline
\end{tabular}




\begin{tabular}{|c|c|c|c|c|c|c|c|}
\hline $1^{\text {st }}$ Place & 220.7 & 239 & 3.99 & 188 & 5.92 & 2.00 & 2.98 \\
\hline $10^{\text {th }}$ Place & 216.8 & 238 & 3.99 & 185 & 5.99 & 2.00 & 2.97 \\
\hline Last Place & 211.6 & 233 & 3.95 & 178 & 5.98 & 2.00 & 3.04 \\
\hline \multicolumn{8}{|c|}{ Chinese GP } \\
\hline $1^{\text {st }}$ Place & 214.6 & 245 & 4.00 & 190 & 5.99 & 2.00 & 3.06 \\
\hline Last Place & 205.1 & 242 & 3.97 & 174 & 5.90 & 2.00 & 3.22 \\
\hline \multicolumn{8}{|c|}{ Azerbaijan GP } \\
\hline $1^{\text {st }}$ Place & 214.7 & 248 & 3.96 & 179 & 5.99 & 2.00 & 3.44 \\
\hline $10^{\text {th }}$ Place & 212.5 & 244 & 3.96 & 175 & 5.97 & 2.00 & 3.51 \\
\hline Last Place & 205.0 & 247 & 3.99 & 183 & 5.97 & 2.00 & 3.60 \\
\hline \multicolumn{8}{|c|}{ Spanish GP } \\
\hline $1^{\text {st }}$ Place & 220.1 & 223 & 3.98 & 168 & 6.00 & 2.00 & 2.47 \\
\hline $10^{\text {th }}$ Place & 217.8 & 218 & 4.00 & 160 & 6.00 & 2.00 & 2.50 \\
\hline Last Place & 209.0 & 214 & 3.99 & 159 & 5.98 & 2.00 & 2.80 \\
\hline \multicolumn{8}{|c|}{ Monaco GP } \\
\hline $1^{\text {st }}$ Place & 169.5 & 137 & 3.99 & 86 & 6.00 & 2.00 & 3.33 \\
\hline $10^{\text {th }}$ Place & 167.7 & 139 & 3.91 & 83 & 6.00 & 2.00 & 3.33 \\
\hline Last Place & 167.2 & 134 & 3.90 & 86 & 6.00 & 2.00 & 3.34 \\
\hline \multicolumn{8}{|c|}{ Canadian GP } \\
\hline $1^{\text {st }}$ Place & 222.3 & 210 & 3.99 & 134 & 5.98 & 2.00 & 2.41 \\
\hline $10^{\text {th }}$ Place & 217.5 & 205 & 3.99 & 131 & 5.99 & 2.00 & 2.46 \\
\hline Last Place & 210.6 & 199 & 3.99 & 129 & 5.89 & 2.00 & 2.74 \\
\hline \multicolumn{8}{|c|}{ French GP } \\
\hline $1^{\text {st }}$ Place & 235.1 & 258 & 4.00 & 202 & 5.98 & 2.00 & 3.00 \\
\hline $10^{\text {th }}$ Place & 232.5 & 260 & 3.97 & 201 & 5.87 & 2.00 & 3.06 \\
\hline Last Place & 225.9 & 256 & 3.97 & 187 & 5.89 & 2.00 & 3.23 \\
\hline \multicolumn{8}{|c|}{ Austrian GP } \\
\hline $1^{\text {st }}$ Place & 248.2 & 245 & 3.99 & 185 & 5.71 & 1.72 & 1.72 \\
\hline $10^{\text {th }}$ Place & 241.5 & 239 & 3.98 & 183 & 5.74 & 1.76 & 1.76 \\
\hline Last Place & 235.8 & 231 & 3.98 & 147 & 5.99 & 2.00 & 2.01 \\
\hline \multicolumn{8}{|c|}{ British GP } \\
\hline $1^{\text {st }}$ Place & 247.1 & 282 & 3.96 & 232 & 5.93 & 2.00 & 2.13 \\
\hline $10^{\text {th }}$ Place & 245.4 & 277 & 4.00 & 232 & 5.89 & 2.00 & 2.38 \\
\hline Last Place & 241.3 & 277 & 3.95 & 227 & 5.99 & 2.00 & 2.27 \\
\hline
\end{tabular}

Page 11 of 16 
In terms of energy deployment side, all the drivers are able to deploy almost $4 \mathrm{MJ}$ of energy from the MGU-K in all the qualification laps at all the circuits. This accounts for an increase in engine power of about a $160 \mathrm{hp}$ for $33.33 \mathrm{secs}$. Table 3 illustrates the comparative analysis of the drivers for each circuit during qualification. The energy that is deployed in this case is all taken from the battery. The MGU-K deployment speed is however different for different drivers at the same circuit. This has a direct co-relation with the lap times clocked by each driver as higher the MGU-K deployment speed, higher will be the top speed and hence faster the car can go. However, the MGU-K deployment speed is not one of the sole variables to determine the lap times clocked and the energy deployed. A lot of other factors come into picture like tyre pressure, aero-balance of the car throughout the circuit, battery power available at the start of the race, etc.

In terms of energy deployment and recovery side, all the drivers are able to deploy almost $6 \mathrm{MJ}$ of energy from the MGU-K (4MJ deployed $+2 \mathrm{MJ}$ recovered and deployed). This accounts for an increase in engine power of about a $160 \mathrm{hp}$ for 50 secs. The energy that is deployed in this case is all taken from the battery including the power recovered as the total energy depletion in the battery cannot be more than $4 \mathrm{MJ}$ at any point of time [4]. The MGU-K deployment speed is however different for different drivers at the same circuit. It is clear from the analysis that the option of using the MGU-K for energy recovery and deployment has far more benefits than using the MGU-K for only energy deployment.

Table 4. Proposed Strategy for MGU-K Deployment Speed for Qualification for Maximum Performance as a multiplication factor of the average vehicle speed during qualification

\begin{tabular}{|l|c|c|}
\hline \multicolumn{1}{|c|}{ Circuit } & $\begin{array}{c}\text { MGU-K Deployment } \\
\text { Speed (kph) }\end{array}$ & $\begin{array}{c}\text { Energy Deployed } \\
\text { (MJ) }\end{array}$ \\
\hline Australian GP & $0.86 \times V_{\text {avg, quali }}$ & 6.00 \\
\hline Bahrain GP & $0.85 \times V_{\text {avg, quali }}$ & 6.00 \\
\hline Chinese GP & $0.87 \times V_{\text {avg, quali }}$ & 6.00 \\
\hline Azerbaijan GP & $0.85 \times V_{\text {avg, quali }}$ & 6.00 \\
\hline Spanish GP & $0.75 \times V_{\text {avg, quali }}$ & 6.00 \\
\hline Monaco GP & $0.51 \times V_{\text {avg, quali }}$ & 6.00 \\
\hline Canadian GP & $0.61 \times V_{\text {avg, quali }}$ & 6.00 \\
\hline French GP & $0.85 \times V_{\text {avg, quali }}$ & 6.00 \\
\hline Austrian GP & $0.70 \times V_{\text {avg, quali }}$ & 5.80 \\
\hline British GP & $0.94 \times V_{\text {avg, quali }}$ & 6.00 \\
\hline
\end{tabular}

It is also observed that even though the MGU-K is able to recover more energy (apart from the Austrian GP circuit), the regulations limit the recovery to a maximum of $2 \mathrm{MJ}$ per lap. The drivers finishing in the top place are able to recover lesser energy as compared to the other drivers. This means that the battery is used more as a power transmission device than a power storage device. Also, due to the fact that these vehicles demand a large amount of energy for a short duration of time, storage of energy for longer periods of time has its own limitations as losses in the battery is a function of charge, resistance and time for which energy being stored.

The proposed regulations for 2021 hint towards giving power deployment control from the ERS to the driver as currently this is done using algorithms. The MGU-K power recovery should be set to unlimited if they MGU-H is removed to increase the efficiency of the subsystem. A correlation is proposed in Table 4 between the MGU-K deployment speed and the average vehicle speed during qualification $\left(\mathrm{V}_{\mathrm{avg}}\right.$, quali $)$. This allows for the driver to understand the optimal speed at which the MGU-K power is deployed for maximum performance.

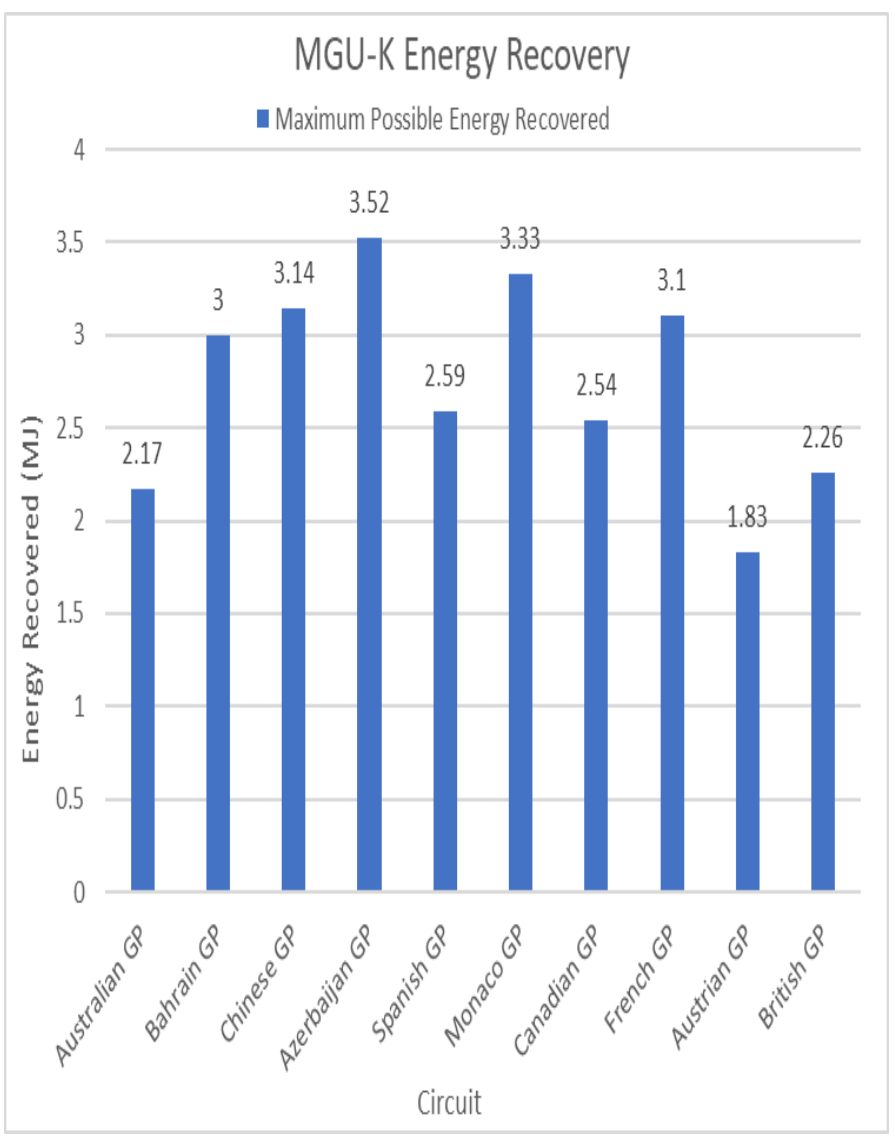

Figure 12. Circuit Specific MGU-K Energy Recovery Values for Qualification

\section{Strategy for Race}

Considering the fuel tank is fully filled with $110 \mathrm{kgs}$ of fuel and the car has a weight of $743 \mathrm{kgs}$ (including driver) at the start of the race (all specified by regulations [4]), the total weight of the car is $853 \mathrm{kgs}$. The race lap simulations are carried out for the 3 drivers for all the 10 circuits. The lap analysis is done starting from the 2 nd Lap of the race until the end of the race. The 1st Lap is not considered in the simulation because a lot of dynamic factors affect the car's performance during the 1st Lap like race start, position of the driver at the race start, initial SOC at the start of the race, etc.

Fuel weight modelling is added to the full car model for race lap analysis as the weight of the car reduces after each lap and this can drastically affect the performance of PU. Emphasis is given to estimate 
the maximum possible energy that can be recovered by the MGU-K per lap. This is done by estimating the total energy recovered by the MGU$\mathrm{K}$ throughout the race and dividing that value by the number of laps completed by the driver. Since the current regulations [4] allow for more energy to be deployed than recovered by the MGU-K, it is very hard to estimate the initial SOC of the battery at the start of each lap. Hence, the above approach is more appropriate. The MGU-K energy recovery is not limited to $2 \mathrm{MJ}$ per lap in race lap analysis to estimate the maximum possible energy that can be recovered.

Power deployment from the MGU-K controller for each lap is not analyzed because of various limitations like change in MGU-K deployment speed in each lap due to reduction in fuel weight, estimation of energy recovery per lap by analyzing lap to lap recovery rather than full race analysis is harder as weight of car changes every second, Initial SOC at the start of each lap is hard to determine as total energy recovered throughout the race is being estimated, etc.

Table 5. Comparative Analysis of Race Data of Drivers for 2019 season where the average vehicle speed is obtained using OCR and the other data is obtained from numerical simulations

\begin{tabular}{|c|c|c|c|}
\hline Driver & $\begin{array}{c}\text { Average } \\
\text { Speed } \\
\text { (kph) }\end{array}$ & $\begin{array}{c}\text { Number of } \\
\text { Laps }\end{array}$ & $\begin{array}{c}\text { MGU-K } \\
\text { Energy } \\
\text { Recovered per } \\
\text { lap (MJ) } \\
\end{array}$ \\
\hline \multicolumn{4}{|c|}{ Australian GP } \\
\hline $1^{\text {st }}$ Place & 214.19 & 57 & 2.61 \\
\hline $10^{\text {th }}$ Place & 210.43 & 56 & 2.77 \\
\hline Last Place & 202.81 & 55 & 2.84 \\
\hline \multicolumn{4}{|c|}{ Bahrain GP } \\
\hline $1^{\text {st }}$ Place & 195.07 & 56 & 3.62 \\
\hline $10^{\text {th }}$ Place & 191.63 & 56 & 3.76 \\
\hline Last Place & 186.92 & 54 & 3.68 \\
\hline \multicolumn{4}{|c|}{ Chinese GP } \\
\hline $1^{\text {st }}$ Place & 197.55 & 55 & 3.52 \\
\hline $10^{\text {th }}$ Place & 193.44 & 54 & 3.77 \\
\hline Last Place & 189.28 & 53 & 3.74 \\
\hline \multicolumn{4}{|c|}{ Azerbaijan GP } \\
\hline $1^{\text {st }}$ Place & 197.83 & 50 & 3.74 \\
\hline $10^{\text {th }}$ Place & 194.75 & 49 & 4.02 \\
\hline Last Place & 188.78 & 48 & 4.15 \\
\hline \multicolumn{4}{|c|}{ Spanish GP } \\
\hline $1^{\text {st }}$ Place & 189.54 & 65 & 3.25 \\
\hline $10^{\text {th }}$ Place & 189.16 & 64 & 3.30 \\
\hline Last Place & 184.79 & 64 & 3.36 \\
\hline \multicolumn{4}{|c|}{ Monaco GP } \\
\hline
\end{tabular}

\begin{tabular}{|c|c|c|c|}
\hline $1^{\text {st }}$ Place & 148.74 & 77 & 3.81 \\
\hline $10^{\text {th }}$ Place & 147.57 & 77 & 3.82 \\
\hline Last Place & 145.22 & 75 & 4.01 \\
\hline \multicolumn{4}{|c|}{ Canadian GP } \\
\hline $1^{\text {st }}$ Place & 203.16 & 69 & 2.73 \\
\hline $10^{\text {th }}$ Place & 199.28 & 68 & 2.75 \\
\hline Last Place & 193.24 & 66 & 2.90 \\
\hline \multicolumn{4}{|c|}{ French GP } \\
\hline $1^{\text {st }}$ Place & 216.88 & 52 & 3.53 \\
\hline $10^{\text {th }}$ Place & 212.42 & 51 & 3.59 \\
\hline Last Place & 206.55 & 50 & 3.89 \\
\hline \multicolumn{4}{|c|}{ Austrian GP } \\
\hline $1^{\text {st }}$ Place & 222.97 & 70 & 2.28 \\
\hline $10^{\text {th }}$ Place & 219.40 & 69 & 2.32 \\
\hline Last Place & 212.91 & 67 & 2.55 \\
\hline \multicolumn{4}{|c|}{ British GP } \\
\hline $1^{\text {st }}$ Place & 223.33 & 51 & 2.70 \\
\hline $10^{\text {th }}$ Place & 220.27 & 51 & 2.98 \\
\hline Last Place & 216.78 & 50 & 3.05 \\
\hline
\end{tabular}

In terms of energy recovered per lap from the MGU-K, it is seen that the energy recovered during race laps is more than the energy recovered during qualification laps as illustrated in Table 5. One of the major reasons for this is that the kinetic energy $(\mathrm{KE})$ that is available during braking is more during the race as the car is heavier. The $\mathrm{KE}$ is dependent on mass of the vehicle and the vehicle velocity attained. This also means that the maximum energy recovered by the MGU-K cannot be solely determined by analyzing the car's performance during qualification only. Analyzing the performance of different drivers on the same GP, it is seen that the driver that has finished the race in the top place is able to recover less energy per lap as compared to other drivers. This is an indicator that the battery is used more as an energy flow device rather than an energy storage device.

Analyzing the race performance for 2019 regulations shown in Table 5, it is clear that a lot of energy that is being recovered from the MGU-K is being wasted as the regulations limit the energy recovery to $2 \mathrm{MJ}$ per lap. It can also be deduced that the average speed of the car throughout the race can be a parameter to determine the performance characteristic of the PU, i.e. higher the average speed of the car, better the performance of the ERS and optimum control of ERS is possible. It can also be seen that drivers in circuits such as Bahrain GP, Azerbaijan GP and Monaco GP are able to recover almost 4MJ of energy per lap from the MGU-K only which would allow for higher energy deployment (close to $8 \mathrm{MJ}$ per lap) to improve the performance of the car and the efficiency the PU for 2021 regulations.

There is a lot of variation in the energy recovered by the MGU-K per lap for different circuits where the value goes from as low as $2.28 \mathrm{MJ}$ per lap in the Austrian GP circuit to $4.15 \mathrm{MJ}$ per lap in the Azerbaijan 
GP circuit as shown in Table 5. The only drawback of this estimation of maximum energy recovered per lap is that specific lap to lap analysis is not possible as the cumulative energy recovery throughout the race is analyzed. There may be a possibility that the car would have recovered more than $5 \mathrm{MJ}$ of energy in one lap and then recovered only $1 \mathrm{MJ}$ in the subsequent lap, but the energy recovered per lap would show $3 \mathrm{MJ}$ of energy recovered per lap for 2 laps. A correlation between average speed of vehicle during qualification $\left(\mathrm{V}_{\mathrm{avg}}\right.$, quali $)$ and average speed of vehicle during the race $\left(\mathrm{V}_{\mathrm{avg}}\right.$, race $)$ has been proposed in Table 6. With this correlation, the MGU-K deployment speed for the whole race can be proposed based on the cumulative energy recovery throughout the race for maximizing the performance of the PU: -

Table 6. Proposed Strategy for MGU-K Deployment Speed for Race for Maximum Performance as a multiplication factor of the average vehicle speed during qualification

\begin{tabular}{|l|l|c|}
\hline \multicolumn{1}{|c|}{ Circuit } & $\mathrm{V}_{\text {avg, race }}(\mathrm{kph})$ & $\begin{array}{c}\text { MGU-K Deployment } \\
\text { Speed }(\mathrm{kph})\end{array}$ \\
\hline Australian GP & $0.91 \times V_{\text {avg, quali }}$ & $0.78 \times V_{\text {avg, race }}$ \\
\hline Bahrain GP & $0.88 \times V_{\text {avg, quali }}$ & $0.75 \times V_{\text {avg, race }}$ \\
\hline Chinese GP & $0.92 \times V_{\text {avg, quali }}$ & $0.80 \times V_{\text {avg, race }}$ \\
\hline Azerbaijan GP & $0.92 \times V_{\text {avg, quali }}$ & $0.78 \times V_{\text {avg, race }}$ \\
\hline Spanish GP & $0.87 \times V_{\text {avg, quali }}$ & $0.65 \times V_{\text {avg, race }}$ \\
\hline Monaco GP & $0.88 \times V_{\text {avg, quali }}$ & $0.45 \times V_{\text {avg, race }}$ \\
\hline Canadian GP & $0.92 \times V_{\text {avg, quali }}$ & $0.56 \times V_{\text {avg, race }}$ \\
\hline French GP & $0.92 \times V_{\text {avg, quali }}$ & $0.78 \times V_{\text {avg, race }}$ \\
\hline Austrian GP & $0.90 \times V_{\text {avg, quali }}$ & $0.63 \times V_{\text {avg, race }}$ \\
\hline British GP & $0.90 \times V_{\text {avg, quali }}$ & $0.85 \times V_{\text {avg, race }}$ \\
\hline
\end{tabular}

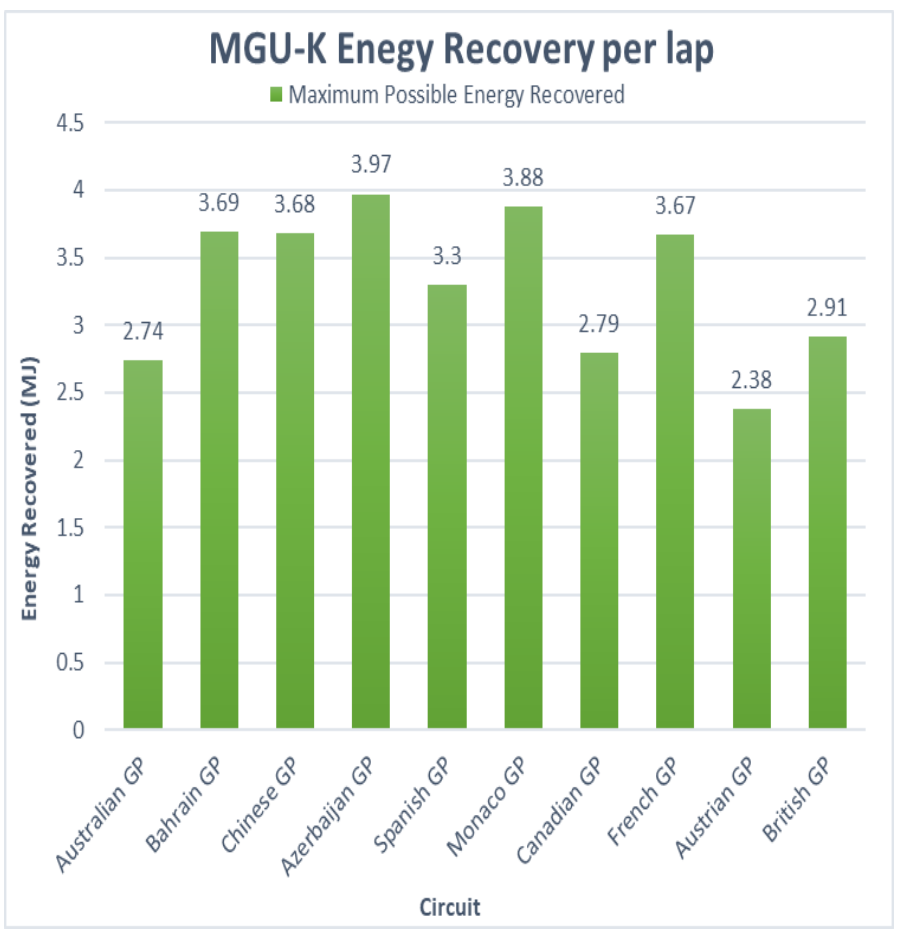

Figure 13. Circuit Specific MGU-K Energy Recovery Values for Race Laps
Key findings from this analysis are:

- The drivers use the MGU-K for both energy recovery and deployment during qualification.

- The Average vehicle speed throughout the circuit is a good performance indicator of the driver's position and the MGUK deployment speed.

- The ERS is used more as an energy flow through device and not as a storage device, i.e. in order to get maximum performance, the drivers need to use almost all the energy they recovered in the same lap and not store it for further laps.

- The current regulations limit the maximum energy recovered by the MGU-K to $2 \mathrm{MJ}$ per lap but in almost all the circuits, the drivers are able to recover more than $2 \mathrm{MJ}$ of energy per lap from the MGU-K.

- $\quad$ The 2021 proposed ERS (Battery, Control Electronics and MGU-K) is able to meet the power demands of the vehicle in order to meet the required vehicle speed at the required gear number.

- The energy recovered per lap is higher during race laps than during the qualification laps as the car is heavier.

- Control Strategies have been proposed for MGU-K deployment speed for both qualification laps and race laps as a multiplication factor to the average vehicle speed. This gives an insight to the speed at which the MGU-K power can be deployed to maximize the performance of the PU.

\section{Conclusion}

The present work aimed to propose a strategy for optimising energy recovery and deployment options for 2021 by maximizing the performance of the hybrid electric powertrain using the 2019 Formula One FIA technical regulations and data obtained from 2019 races. A V6 Engine was modelled in GT-Power which was complaint to all the FIA regulations pertaining to Powertrain to obtain the data for ICE and MGU-H. The data required for validating and comparing the PU was obtained from real-time on-board video data extraction from F1 TV App.

OCR for image to data conversion was implemented to get vehicle speed, engine speed and gear number of each driver. With this information, the shift speeds of different drivers were compared and the gearbox sizing was chosen along with the derived information of under-gearing ratio. Once the data extraction was complete, a full car model fully compliant to the FIA technical and sporting regulations was developed in GT-Drive. The model was validated by the 2019 Pole Position Lap at the Australian GP and compared against published FIA results. Once the model was validated for the 2019 regulations, suitable changes were incorporated in the energy transfer controllers to remove the energy deployment and recovery from the MGU-H for the analysis of the PU for the proposed 2021 regulations. The model is re-validated for the 2021 regulations with driver on-board data of 2019 season to make sure it is complaint to regulations in all aspects. 
The performance of the PU was analyzed for both the qualification laps and race laps of 3 drivers (Race Winner, 10th Place driver and Race Finisher on last position) for the first 10 circuits in the 2019 FIA Formula One World Championship ${ }^{\circledR}$. The data extracted from F1 TV app is fed as input to the numerical model for evaluating the PUs performance. From the results of the simulation it was seen that the ERS was used more as an energy flow device rather than an energy storage device. The drivers finishing in the top places were able to recover the least amount of energy as compared to other drivers because the control logic of ERS system in their car focussed more on energy deployment and recovery rather than energy recovery, storage and deployment.

Lastly, control strategies were proposed after analyzing the results of the qualification laps and race laps. It was seen that the average vehicle speed of the car throughout the circuit was a good performance measure of estimating the PUs performance. Based on the results, a correlation / formula has been proposed for vehicle speed at which MGU-K power needs to be deployed in-order to maximize the performance of the car during qualification for each of the 10 circuits. It can also be seen that the PU is able to meet all the power demands of the driver with only the MGU-K. As it is extremely difficult to estimate the lap to lap energy recovery and deployment options due the current regulations allowing for more energy to be deployed than to be recovered, the cumulative energy recovered throughout the race is a good performance measure for estimating the maximum possible energy recovered per lap.

The approach proposed and the modelling scheme followed has proven to be reliable and accurate for estimating the performance envelope of a hybrid electric powertrain of an F1 car. This model can be used to size and test the components of the ERS of an F1 car for different circuits to maximize performance.

\section{References}

1. Otero, V.T. and Samuel, S., "Numerical Simulation of a 2018 F1 Car Cooling System for Silverstone Circuit," SAE Technical Paper 2018-01-0169, 2018, doi:10.4271/2018-01-0169

2. Understanding F1 ERS. [Online] Available at: https:/www.formula1.com/en/championship/insidefl/understanding-fl-racing/Energy_Recovery_Systems.html

3. F1 Power Unit and ERS Rules. [Online] Available at: https://www.formula1.com/en/championship/inside-fl/rulesregs/Power_Unit_and_ERS.html

4. Formula One Technical Regulations 2019, Federation Internationale de l'Automobile, Published on March 12, 2019

5. D Edmondson L (2017) Is an F1 car more energy efficient than an electric vehicle? [Online] Available at: http://www.espn.co.uk/f1/story/_id/15152695/is-f1-car-moreenergy-efficient-electric-vehicle

6. Formula One Sporting Regulations 2019, Federation Internationale de l'Automobile, Published on December 05, 2018

7. Kempynck T (2014) Restarting Engines. Racecar Engineering. (Vol 24 No 5), 59

8. Perrinn (2019) PERRINN wiki. [Online] Available at: https://docs.google.com/document/d/1IjmDbmcW2IDg5Kj9ENp Y3_Fw-oHv3RCJ2f8ZJdbjRpk/pub\#h.faulr6622qmi
9. UK Government, Gov.Uk. [Online] Available at: https://www.gov.uk/government/uploads/system/uploads/attach ment_data/file/446487/dukesa_1-a_3.xls

10. Mercedes AMG F1 W10 EQ Power+. [Online] Available at: https://en.wikipedia.org/wiki/Mercedes_AMG_F1_W10_EQ_Po wer\% $\%$ B

11. Brown C (2011) Making sense of squiggly lines. Huntington Beach, Calif.: Christopher Brown Racing pg26

12. On-board Timing Information. [Online] Available at: https://www.formula1.com/en.html

13. Heisler H (1995) Advanced engine technology. London [u.a.]: Arnold

14. Engauge Digitizer. (2019). markummitchell.

15. Ludvigsen, K. (2002). Classic racing engines. Sparkford: Haynes

16. On-board Telemetry Data. [Online] Available at: https://f1tv.formula1.com/en/

17. M. T. Qadri and M. Asif, "Automatic Number Plate Recognition System for Vehicle Identification Using Optical Character Recognition," 2009 International Conference on Education Technology and Computer, Singapore, 2009, pp. 335-338. doi: 10.1109/ICETC.2009.54

18. Recognize Text Using OCR. [Online] Available at: https://in.mathworks.com/help/vision/examples/recognize-textusing-optical-character-recognition-ocr.html

19. OCR Matlab Documentation and Description. [Online] Available at: https://in.mathworks.com/help/vision/ref/ocr.html

20. Formula One World Championship season 2019 details. [Online] Available at: https://www.fia.com/events/fia-formula-oneworld-championship/season-2019/2019-fia-formula-one-worldchampionship

21. Bengolea F and Samuel S (2016) Technology Choices for Optimizing the Performance of Racing Vehicles. SAE Technical Paper Series

22. F1 2021 Hinted Regulations. [Online] Available at: https://www.formula1.com/en/latest/article.formula-1-in-2021where-we-stand-and-what-happensnext.3f4zgyDjeERMFtxaymbncK.html

\section{Nomenclature}

\begin{tabular}{|c|c|}
\hline $\mathrm{P}$ & Power \\
\hline$\dot{\mathrm{m}}_{\text {fuel }}$ & Mass flow rate of fuel \\
\hline$\eta_{\text {thermal }}$ & Thermal efficiency \\
\hline $\mathrm{Q}_{\mathrm{HV}}$ & Calorific value \\
\hline $\mathrm{RPM}_{\mathrm{ICE}}$ & Revolutions per minute of internal combustion \\
\hline$\lambda$ & Lambda \\
\hline$\dot{\mathrm{m}}_{\text {air }}$ & Mass flow rate of air \\
\hline$\dot{\mathrm{m}}_{\text {total }}$ & Total mass flow rate \\
\hline$\dot{\mathrm{m}}_{\mathrm{air}, \mathrm{NA}}$ & $\begin{array}{r}\text { Mass flow rate of air for a naturally aspirated } \\
\text { engine }\end{array}$ \\
\hline $\mathrm{n}_{\text {open, cylinders }}$ & Number of cylinders open \\
\hline $\mathrm{V}_{\text {ICE }}$ & Volume (capacity) of internal combustion engine \\
\hline $\mathrm{n}_{\text {cylinders }}$ & Number of cylinders \\
\hline$\eta_{\mathrm{vol}}$ & Volumetric efficiency \\
\hline$\rho_{\text {air }}$ & Density of air \\
\hline
\end{tabular}




\begin{tabular}{|c|c|}
\hline $\mathrm{n}_{\text {rev per intake }}$ & Revolutions for intake stroke \\
\hline $\mathrm{P}_{\text {MGU-H, Recovery }}$ & MGU-H power transfer during recovery \\
\hline $\mathrm{P}_{\text {MGU-H, Deployment }}$ & MGU-H power transfer during deployment \\
\hline $\mathrm{E}_{\text {turbine, }}$ PID & Turbine energy using a PID controller \\
\hline $\mathrm{E}_{\text {turbine, closed WG }}$ & Turbine energy with waste gate closed \\
\hline$\omega_{\text {shaft required to meet m } \dot{m}_{\text {fuel }}}$ & $\begin{array}{r}\text { Rotational speed of the turbocharger shaft to meet } \\
\text { the targeted mass flow rate of fuel }\end{array}$ \\
\hline $\mathrm{E}_{\text {compressor, controlled shaft }}$ & $\begin{array}{r}\text { Compressor energy with imposed turbocharger } \\
\text { shaft speed }\end{array}$ \\
\hline $\mathrm{E}_{\text {compressor, } \mathrm{PID}}$ & Compressor energy using a PID controller \\
\hline$i_{o} i_{\theta}$ & Transmission Ratio \\
\hline $\mathrm{F}_{\text {tractive }}$ & Tractive Force \\
\hline $\mathrm{m}$ & Mass of the vehicle \\
\hline $\mathrm{g}$ & Gravitational acceleration $\left(9.81 \mathrm{~m} / \mathrm{s}^{2}\right)$ \\
\hline$\alpha$ & Angle of incline from level road \\
\hline$A_{\text {frontal }}$ & Frontal area \\
\hline V & Velocity of the vehicle \\
\hline $\mathrm{c}_{\mathrm{d}}$ & Coefficient of discharge \\
\hline $\mathrm{c}_{\mathrm{r}}$ & Coefficient of rolling resistance \\
\hline $\mathrm{c}_{\mathrm{L}}$ & Coefficient of lift \\
\hline $\mathrm{T}_{\text {tractive }}$ & Tractive torque \\
\hline $\mathrm{r}_{\text {wheel,corrected }}$ & Wheel radius corrected (including tyre) \\
\hline $\mathrm{T}$ & Torque \\
\hline
\end{tabular}

\section{Contact Information}

\section{Karan Bopaiah}

Oxford Brookes University

karanbopaiah@gmail.com

\section{Stephen Samuel}

Oxford Brookes University

s.samuel@brookes.ac.uk 